\title{
О РОЛИ ГИПЕРО-ГИПОНИМИЧЕСКИХ ОТНОШЕНИЙ В ФОРМИРОВАНИИ ЗАИМСТВОВАННОЙ ТЕХНИЧЕСКОЙ ТЕРМИНОЛОГИИ
}

\section{THE ROLE OF HYPERO-HYPONYMIC RELATIONS IN THE FORMATION OF BORROWED TECHNICAL TERMINOLOGY}

R. Yakhina

Summary:This article is devoted to the study of hyper-hyponymic relations issue on the material of technical terminology. The extra-linguistic factors influencing the intensity of penetration of foreign language vocabulary are considered. The relevance of the work is in the possibility of applying the results of research in the creating lexicographic sources.

Keywords: hyponym, hyperonym, term, terminology, borrowings.
$\mathrm{B}$ опросы определения гиперо-гипонимических отношений слов и терминов в настоящее время представляют особый интерес как при составлении словарей для различных целей, так и разработки поисковых информационных систем. Целью данной работы является исследование особенностей функционирования гиперонимов и гипонимов в научно-популярном дискурсе.

В настоящее время терминология составляет значительный лексико-фразеологический слой языка науки, используемый в профессиональной деятельности [4, c. 91]. Это объясняется тем, что в термине отражается стремление человека к рационализации и оптимизации общения как в письменной, так и в устной форме.

Совокупность понятий науки, иной области знаний формируют её терминологию. Среди исследователей современной лингвистики существует тенденция разграничения понятий «терминология» и «терминосистема» [11, с. 17]. Мы можем определить терминологию как совокупность слов и словосочетаний, обозначающих специальные понятия, применяемые в коммуникации в определенной области знаний. Терминологическая система является упорядоченное и структурированное множество терминов определенной области знаний, то есть кодифицированная и унифицированная терминология.

Базовым элементом указанных понятий является термин. Как считает А.А. Реформатский, термин - это слова специальные, ограниченные своим особым назначением; слова, стремящиеся быть однозначными как точное выражение понятий и наименование вещей. Подлинные термины должны быть «отграничены» от полисемии,

\author{
Яхина Рузиля Раифовна \\ К.филол.н., дочент, Казанский национальный \\ исследовательский технический университет \\ им. А.Н. Туполева -КАИ \\ Shroza1981@yandex.ru
}

Аннотация: Данная статья посвящена изучению вопроса гиперо-гипонимических отношений на материале технической терминологии. Рассмотрены экстралингвистические факторы влияющие на интенсивность проникновения иноязычной лексики. Актуальность работы заключается в возможности использования результатов при создании лексикографических источников.

Ключевые слова: гипоним, гипероним, термин, терминосистема, заимствования.

от экспрессивности и тем самым от обычных нетерминологических слов, которые как раз по преимуществу многозначны и экспрессивны [10, с. 61-62]. Формулировка универсальной дефиниции понятия термин была и остается одной из актуальных задач терминоведения. Нет единого мнения относительно определения термина, попытки дать краткое и четкое определение понятию термин не прекращаются и по сей день.

К.А. Мякшин в работе посвященной проблеме разнообразия подходов определения понятия термин, приводит следующее определение: термин - это общепринятое частотное слово (словесный комплекс), характеризующееся единством звукового облика и соотнесенного с ним соответствующего понятия в системе понятий данной области знания и деятельности, и отличающееся от остальных номинативных единиц системным характером, семантической целостностью, контекстуальной независимостью, моносемантичностью и стилистической нейтральностью [8, с. 110].

На основании определений, существующих у различных авторов, мы можем перечислить основные признаки (требования) терминов:

- моносемантичность (однозначность) и нейтральность. Например, в ГОСТ Р ИСО 704-2010 это требование интерпретируется следующим образом: термин должен быть максимально нейтральным, нежелательно использование слов с второстепенными или отрицательными значениями.

- краткость (лингвистическая экономия). Длинные, громоздкие наименования в текстах часто могут 
замещаться многоточием, либо аббревиатурами, что, в свою очередь, снижает доступность текста для восприятия.

- деривационная продуктивность. При формировании терминологии отдается предпочтение терминам, позволяющим получать производные и сложные слова.

- лингвистическая корректность. Термины и наименования должны соответствовать нормам языка;

- системность. Термин должен иметь четкую позицию (родовидовые связи, партитивные отношения с другими терминами) в системе терминов области знаний, в которой функционирует. В родовых отношениях объем главного понятия включает соответствующее подчиненное понятие, следовательно, гипо-гиперонимические отношения позволяют формировать краткие дефиниции (определения) терминов.

Упорядоченность и иерархичность понятий характеризует степень изученности тех или иных областей знаний. Стремление к выявлению иерархии, системности является основной движущей силой любой науки, в которой умозаключения от общего к частному (дедукция) или от частного к общему (индукция) являются важнейшими способами познания.

Система терминов строго иерархична и абсолютное большинство терминов имеют гиперо-гипонимические связи, т.е. имеют родо-видовые семантические связи. Исследование родо-видовых отношений рассматривают обращаясь к функциональному аспекту.

Например, в технике: Устройство-> устройство для коммуникации-> телефон-> мобильный телефон-> смартфон. В науке: Частицы вещества-> молекулы, атомы, субатомные частицы. В то же время, термин субатомные частицы является гиперонимом для терминов электрон, протон, нейтрон. Частича вещества-> субатомная частица-> электрон.

На лексико-семантическом уровне языка гипонимия является одним из системных отношений, гиперо-гипонимические отношения важны в формировании языковой картины мира. Существуют различные взгляды на статус гиперо-гипонемических отношений в лексической системе языка. Мы будем придерживаться мнения о том, что гиперо-гипонимические отношения входят в число важнейших универсальных связей лексической единицы измерения. Гипонимия, основанная на логико-семантическом подчинении, является фундаментальным отношением, определяющим иерархическую структуру отдельных семантических полей (групп) и лексической системы языка в целом, структурируя словарный состав языка.

Вопросу изучения гиперо-гипонимические связей посвящены работы многих ученых начиная с середины XX века таких как Ш. Балли, Дж. Лайонеза. К современным ученым изучающих родо-видовые связи относятся М.В. Лысякова, Е.Е. Котцова и т.д. По мнению Е.Е. Котцовой «гипонимы важные средства когнитивной обработки информации, категоризации лексики - одного из важнейших процессов в познавательной деятельности человека» [6, с. 79]. М.В. Лысякова считает, что гипо-гиперонимические отношения часто встречающееся явление в терминологических системах, которое помогает систематизировать профессиональные наименования. Выделяет три типа отношений: гиперонимии (родо-видового), гипонимии (видо-родового) и согипонимии (видо-видового) [7, с. 23]. М.В. Никитин рассматривает родо-видовые отношения как основной фактор семантической организации словаря в различных профессиональных сферах. Благодаря этим семантическим отношениям «словарь предстает как целостная иерархическая структура» [9, с. 357].

При рассмотрении отношений гипонимии и синонимии выявляется «общее семантическое ядро», но в отличие от синонимии, гипонимия определяется в терминах односторонней замены. В тексте возможна эквивалентная замена гипонима на гипероним как подведение вида под род, обратное же не всегда возможно [3, с. 181]. Следует отметить, что одной из задач стандартизации и систематизации терминов является формирование четкого соответствия пар «термин - понятие», что подразумевает полное исключение синонимичности в терминосистемах.

Нельзя отрицать того факта, что современные этапы развития науки и техники характеризуются лавинообразном ростом информации во всех областях знаний и деятельности. Это, в свою очередь, влечет за собой появление огромного количества новых понятий. Основой для наименования этих понятий может быть как общеупотребительная лексика, так и узкоспециальные термины других языков.

Заимствование из других языков распространенная форма создания нового термина и является одним из наиболее продуктивных способов пополнения словарного запаса любого языка. Заимствованные термины обладают преимуществом перед иными общеупотребительными словами, т.к. изначально обладают свойствами нейтральности, однозначности. Кроме того, в английском языке широко распространённый словообразовательный способ - сращение, что соответствует принципу краткости терминов. Пример, смартбоард по сравнению с интерактивной доской. Устоявшиеся схемы адаптации англоязычных слов (например, tion - ция: computerization - компьютеризация, ing - вание: lapping лаппингование) также представляют дополнительное преимущество перед другими способами терминообра- 
зования (номинации терминов).

Интенсивность вхождения иноязычных лексических единиц зависит от следующих экстралингвистических факторов:

- языковая политика страны;

- частотность применения термина в международном уровне;

- необходимость применения термина в рамках международных отношений.

Стремление к гармонизации терминологии с международными стандартами, интенсификация процессов международной кооперации создают существенные преимущества для интеграции терминов иноязычного происхождения в русские терминосистемы.

Место и объем заимствований терминосистемах определяется степенью сформированности самой терминосистемы, динамичности развития области знаний, термины иноязычного (английского) происхождения термины занимают разную позицию в иерархии терминосистемы. В зависимости от места в родо-видовых отношениях с другими терминами мы выделяем следующие модели:

1. Родовым термином является слово или словосочетание, образованное на русской почве, видовым термином является слово-англицизм. Такая модель наиболее часто встречается в устоявшихся терминосистемах и возникновение видовых слов связано с необходимостью номинации устройств, узлов усовершенствованных, с измененными свойствами по отношению к родовому термину. Например, в наши дни компоновка самолетов достаточно сформирована и не претерпевает существенные изменения при проектировании, но конструкторы в целях повышения управляемости и снижения расхода топлива вносят изменения в отдельные конструктивные элементы, которые получают новые наименования. Элементы механизации крыла: элерон, элевон, спойлерон, флапперон. Элементы законцовки крыла: винглет, шарклет.

у Boeing 737-800 NG современные новые двигатели, законцовки крыльев, узкий фюзеляж и композитные материалы - все это позволяет экономить на расходе топлива [5, с. 25]. Моменты от одних аэродинамических сил можно компенсировать моментами от других аэродинамических сил, что можно проследить на примере крыла с винглетами - законцовками крыла в виде вертикальных крылышек [2, с. 48]. В показательных полетах приняли участие самый большой пассажирский самолет в мире А380, военно-транспортный самолет нового поколения A400M, а также А320, оборудованный шарклетами [1, с. 85].
2. Родовым термином является слово или словосочетание, образованное на русской почве, видовым термином - калька, при этом в литературе дается предпочтение краткому обозначению - иноязычной аббревиатуре. Такая модель наиболее часто функционирует в областях науки и техники с тесным международным сотрудничеством и связана с необходимостью формирования единой межнациональной терминосистемы. Например, в аэронавигации, виды времени: расчетное время прибытия (прилета) - ETA, расчетное время убытия (вылета) - ETD. В автомобильной промышленности для наименования видов двигателей внутреннего сгорания используются: TDI - турбированный инжекторный двигатель, работающий на дизельном топливе, TSI - турбированный инжекторный двигатель, работающий набензине.

3. Родовым и видовыми терминами являются заимствованные слова или словосочетания. Такая модель наиболее часто встречается в динамически развивающихся областях науки и техники, когда новые технологий позволяют создавать новые типы устройств, требующих номинации как самих устройств, так и типа таких устройств. Например, компьютер, ноутбук, нетбук. В данном случае компьютер является гиперонимом для терминов ноутбук, нетбук.

4. Родовой термин является основой словгипонимов, формируемых путем добавления уточняющих компонентов к слову-гиперониму. Модель выявляется в областях техники более близких конечным потребителям и используется для обозначения применяемой технологии, уточнения специфики, важной конечным потребителям.

Например, термин коптер является гиперонимом к терминам-согипонимам бикоптер, квадрокоптер, октокоnтер. Konmep (сокр. от англ. helicopter) -'летательный аппарат, снабженный несколькими несущими винтами'. Наименования вариантов реализации коптеров (терминов-гипонимов), образованы путем добавления элемента би-, квадро-, окто-. В электронике примером может выступать термин роутер ->3G-роутер, 4G-poymep, WiFi-poymep.

Итак, видовые отношения способствуют активному пополнению лексического состава современного русского языка. Объем и место заимствованных терминов в терминосистемах различных отраслей науки и техники зависит от многих факторов, в том числе от таких экстралингвистических факторов как интенсивность участия отрасли в международной кооперации, динамичность развития области знаний. Изучение гиперо-гипонимических отношений дает лингвистам точнее определить семантическое наполнение терминологических систем. 
ЛИТЕРАТУРА

1. Аралов Г. Авиашоу в небе Берлина / Г. Аралов, У. Унгер // Крылья Родины. - 2012. - № 10-11. - С. 84-89.

2. Арасланов С. Основы авиации. Основы прочности / С. Арасланов // Авиация общего назначения. - 2015. - № 11. - С. 46-54.

3. Гурьянова 0.А. Гиперо-гипонимические отношения в английской терминологии телевидения / 0.А. Гурьянова // Филологические науки. Вопросы теории и практики. - 2019. - Т. 12. - № 7. - С. 180-184.

4. Дашкова Г.В. О социолингвистической функции терминасокращения: на материале терминологии вычислит, техн. В англ. и рус. Яз. / Г.В. Дашкова // Язык и общество. Отражение социальных процессов в лексике. - Саратов: Изд-во СГУ, 1986. - С. 91-93.

5. Дмитриев А. Это наша «Победа» / А. Дмитриев // Огонек. - 2019. - № 48 (5590). - С. 24-25.

6. Котцова Е.Е. Гипонимические связи слов в тексте / Е.Е. Котцова // Вестник Поморского университета. Серия: гуманитарные и социальные науки. - 2009. - T. 6. - C. 78-84.

7. Лысякова М.В. Гиперо-гипонимическая таксономия в терминологии / М.В. Лысякова // Вестник РУДН, сер. Лингвистика. - 2006. - № 8. - С. 23-28.

8. Мякшин К.А. Разнообразие подходов к определению понятия «термин» / К.А. Мякшин // Альманах современной науки и образования. - 2009. - Т. 2. № 8 (27). - С. 109-111.

9. Никитин М.В. Курс лингвистической семантики / М.В. Никитин. - 2-е изд. - СПб.: Изд-во РГПУ им.А.И.Герцена, 2007. - 819 с.

10. Реформатский А.А. Введение в языкознание: учебник для вузов / А.А. Реформатский. - М.: Аспект Пресс, 2006.

11. Рыбакова А.С. Определение понятиям терминосистема на примере компьютерных терминов / А.С. Рыбакова // Современный научный вестник. 2014. - T. 5. - № 1. - C. 16-23.

(с Яхина Рузиля Раифовна (Shroza1981@yandex.ru).

Журнал «Современная наука: актуальные проблемы теории и практики»

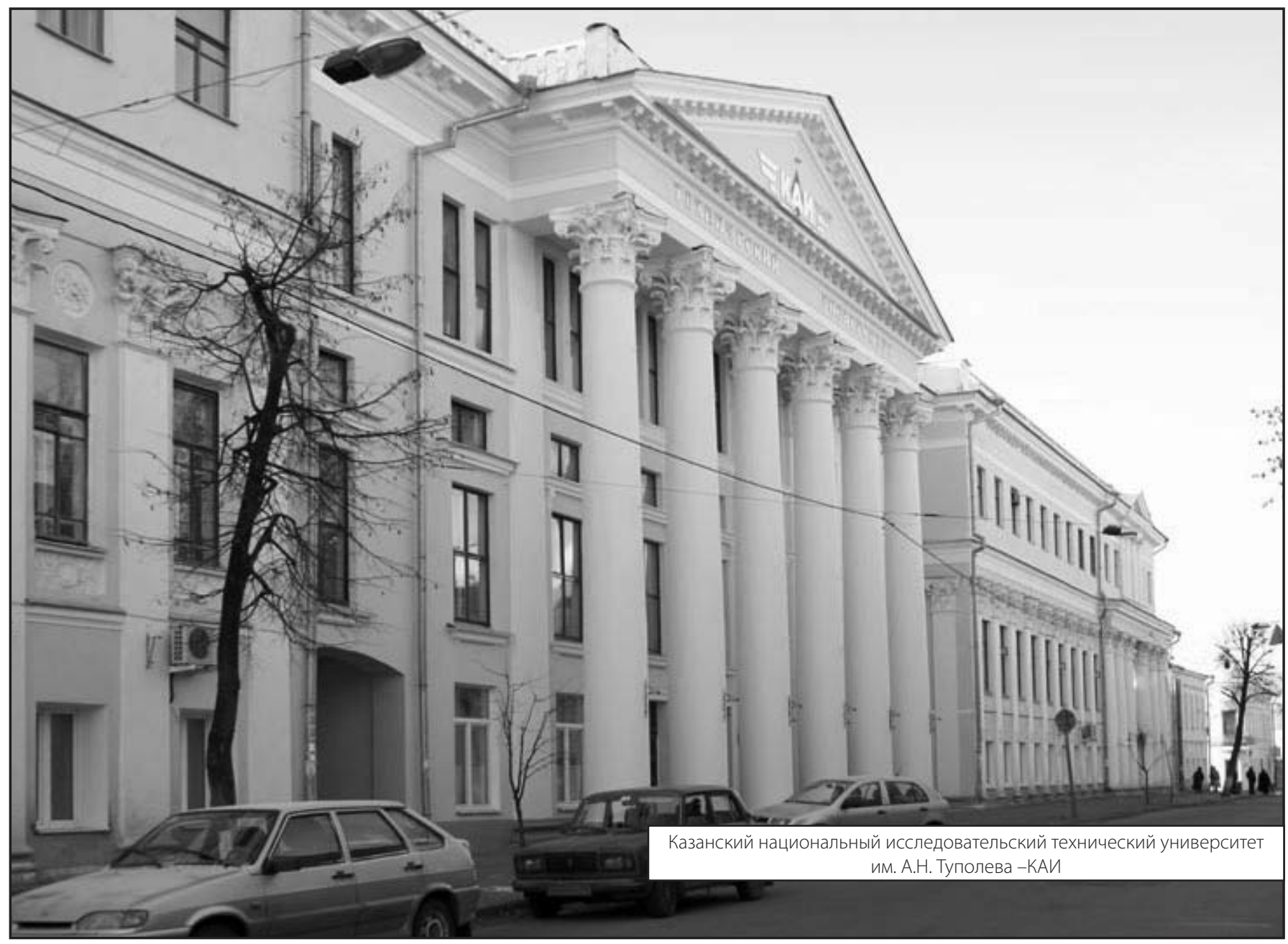

